\title{
Temporal changes in pain processing after whiplash injury, based on Quantitative Sensory Testing: A systematic review
}

Citation for published version (APA):

Bontinck, J., Lenoir, D., Cagnie, B., Murillo, C., Timmers, I., Cnockaert, E., Bernaers, L., Meeus, M., \& Coppieters, I. (2022). Temporal changes in pain processing after whiplash injury, based on Quantitative Sensory Testing: A systematic review. European Journal of Pain, 26(1), 227-245.

https://doi.org/10.1002/ejp.1858

Document status and date:

Published: 01/01/2022

DOI:

10.1002/ejp.1858

Document Version:

Publisher's PDF, also known as Version of record

Document license:

Taverne

Please check the document version of this publication:

- A submitted manuscript is the version of the article upon submission and before peer-review. There can be important differences between the submitted version and the official published version of record.

People interested in the research are advised to contact the author for the final version of the publication, or visit the DOI to the publisher's website.

- The final author version and the galley proof are versions of the publication after peer review.

- The final published version features the final layout of the paper including the volume, issue and page numbers.

Link to publication

\footnotetext{
General rights rights.

- You may freely distribute the URL identifying the publication in the public portal. please follow below link for the End User Agreement:

www.umlib.nl/taverne-license

Take down policy

If you believe that this document breaches copyright please contact us at:

repository@maastrichtuniversity.nl

providing details and we will investigate your claim.
}

Copyright and moral rights for the publications made accessible in the public portal are retained by the authors and/or other copyright owners and it is a condition of accessing publications that users recognise and abide by the legal requirements associated with these

- Users may download and print one copy of any publication from the public portal for the purpose of private study or research.

- You may not further distribute the material or use it for any profit-making activity or commercial gain

If the publication is distributed under the terms of Article $25 \mathrm{fa}$ of the Dutch Copyright Act, indicated by the "Taverne" license above, 


\title{
Temporal changes in pain processing after whiplash injury, based on Quantitative Sensory Testing: A systematic review
}

\author{
Jente Bontinck ${ }^{1,2}$ (iD \\ Inge Timmers ${ }^{3,4,5}$ \\ | Dorine Lenoir ${ }^{1,2}$ \\ | Barbara Cagnie ${ }^{1}$ \\ Carlos Murillo ${ }^{1,2}$ \\ Iris Coppieters ${ }^{2,7}$

\footnotetext{
${ }^{1}$ Department of Rehabilitation Sciences and Physiotherapy, Faculty of Medicine and Health Sciences, Ghent University, Ghent, Belgium

${ }^{2}$ Pain in Motion Research Group (PAIN), Department of Physiotherapy, Human Physiology and Anatomy (KIMA), Faculty of Physical Education \& Physiotherapy, Vrije Universiteit Brussel, Brussels, Belgium

${ }^{3}$ Department of Rehabilitation Medicine, Maastricht University, Maastricht, Netherlands

${ }^{4}$ Department of Cognitive Neuroscience, Maastricht University, Maastricht, Netherlands

${ }^{5}$ Department of Anesthesiology, Perioperative, and Pain Medicine, Stanford University, Palo Alto, CA, United States

${ }^{6}$ Department of Rehabilitation Sciences and Physiotherapy (MOVANT), Faculty of Medicine and Health Sciences, University of Antwerp, Antwerp, Belgium

${ }^{7}$ Department of Physical Medicine and Physiotherapy, University Hospital Brussels, Brussels, Belgium
}

\section{Correspondence}

Mira Meeus, Department of

Rehabilitation Sciences, Ghent

University, Corneel Heymanslaan 10

(3B3), 9000 Ghent, Belgium.

Email: mira.meeus@UGent.be

\section{Funding information}

Jente Bontinck and Dorine Lenoir are funded for this research by The Special Research Fund of Ghent University (respectively, BOF 01962334; BOF19/ DOC/170) and Iris Coppieters is funded by the Research Foundation Flanders (FWO), Belgium (Grant nr. G007217N and G001419N).

\begin{abstract}
Background and Objective: After whiplash injury, some patients develop chronic whiplash-associated disorders. The exact pathophysiology of this chronification is still unclear and more knowledge is needed regarding the different post-injury phases. Therefore, studies were searched that examined temporal changes in pain processing, measured by Quantitative Sensory Testing (QST).

Databases and Data Treatment: This systematic review searched three electronic databases (Medline, Web of Science and Embase) for articles meeting the eligibility requirements. Risk of bias was assessed according to a modified Newcastle-Ottawa Scale.

Results: The 12 included studies presented moderate to good methodological quality. These studies showed altered pain processing within the first month after injury and normalization within 3 months in 59\%-78\% of the patients. After 3 months, recovery stagnates during the following years. Thermal and widespread mechanical hyperalgesia occur already in the acute phase, but only in eventually non-recovered patients. Conclusions: Differences in pain processing between recovering and nonrecovering patients can be observed already in the acute phase. Early screening for signs of altered pain processing can identify patients with high risk for chronification. These insights in temporal changes show the importance of rehabilitation in the acute phase. Future research should target to develop a standardized (bedsite) QST protocol and collect normative data which could, in relation with selfreported pain parameters, allow clinicians to identify the risk for chronification.
\end{abstract}


Significance: Altered pain processing is present soon after whiplash injury, but usually recovers within 3 months. Non-recovering patients show little to no improvements in the following years. Differences between recovering and non-recovering patients can be observed by Quantitative Sensory Testing already in the acute phase. Therefore, it is considered a feasible and effective tool that can contribute to the identification of high-risk patients and the prevention of chronification.

\section{\begin{tabular}{l|l}
1 & INTRODUCTION
\end{tabular}}

The proportion of patients developing a chronic condition after whiplash injury is around $38 \%$, which is remarkably high (Al-Khazali et al., 2020). Even without a detectable pathological lesion at physical examinations or imaging techniques, symptoms can maintain (Ronnen et al., 1996). Chronic Whiplash-associated disorders (WAD) are characterized as heterogeneous conditions, of which the exact pathophysiology is still unclear (Walton \& Elliott, 2017).

Current research showed that changes in central processing of sensory input play an important role in the discrepancy between objective signs of tissue damage and complaints (Harte et al., 2018). After acute injury, hypersensitivity of the peripheral nociceptors occurs, known as peripheral sensitization. When pain persists, central sensitization can arise and cause pain sensations that are no longer in proportion with the noxious peripheral stimuli (Latremoliere \& Woolf, 2009). This discrepancy is frequently seen in WAD (Van Oosterwijck et al., 2013) and other chronic pain disorders; such as fibromyalgia (Banic et al., 2004), rheumatoid arthritis (Meeus et al., 2012) and osteoarthritis (Lluch et al., 2014).

Although no gold standard is available to assess pain processing, Quantitative Sensory Testing (QST) is commonly utilized (Uddin \& MacDermid, 2016). This includes a composition of different techniques to assess the subjective response to controlled stimulation of somatosensory afferents. The purpose of QST is to provide a detailed and reliable representation of pain processing (Boivie, 2003; Curatolo, 2011). Widespread sensory hypersensitivity for a variety of stimuli, indicative of central sensitization, is a consistent feature of chronic WAD and is suspected to contribute to the chronification of pain (Van Oosterwijck et al., 2013). Next to hypersensitivity, the following signs are demonstrated: (1) decreased sensation detection for thermal, electrical and mechanical stimuli (Chien et al., 2009), (2) higher sensitivity during the Brachial Plexus Provocation Test (BPPT) (Stone et al., 2013), (3) decreased Nociceptive Flexion Reflex (NFR) thresholds (Lim et al., 2011), (4) deficient inhibitory endogenous pain modulation (Serrano-Munoz et al., 2019) and (5) enhanced temporal summation (Van Oosterwijck et al., 2013).

Central alternations occur already shortly after injury (Sterling et al., 2004). Widespread mechanical hypersensitivity is present within the first weeks and persists in patients who do not fully recover (Marcuzzi et al., 2015). Note that these conclusions are solely based on studies with a short follow up. It is unclear how somatosensory functions evolves from the acute to later phases. This is, however, crucial in the understanding of the development of chronic WAD. Furthermore, most prospective studies are solely based on pain scales and questionnaires. A meta-analysis (Kamper et al., 2008) reported that pain and disability reduce in most individuals within the first 3 months. Little improvement was seen beyond this point. The question arises if QST measurements show a similar pattern.

As such, a greater understanding of the processes throughout the different post-injury phases may contribute to better treatment strategies in accordance with the underlying mechanisms. Therefore, the aim of this paper was to systematically review the temporal changes in pain processing — measured by QST—after whiplash injury.

\section{\begin{tabular}{l|l}
2 & METHODS
\end{tabular}}

\subsection{Protocol and registration}

This systematic review follows the Preferred Reporting Items for Systematic Reviews and Meta-analyses (PRISMA) guidelines (Moher et al., 2010). The protocol of this systematic review was registered at PROSPERO (registration number: CRD42020176236).

\section{2 | Eligibility criteria and study selection}

In order to perform eligibility assessment, the following inclusion criteria were set up to screen the obtained articles: (1) > 18 years old, (2) diagnosis of whiplash, (3) assessment of QST, (4) a longitudinal study design or studies that cross-sectionally compared patients with acute and chronic WAD or Randomized Controlled Trials that described the evolution of a control group and (5) written in English, Dutch, German or French (Table 1). In the screening of title and abstract, two independent and blinded researchers (J.B. and D.L.) 
assessed the eligibility of the articles. Subsequently, the remaining articles were screened based on full text. In case of disagreements, consensus was obtained by discussion between the two reviewers or by involving a third reviewer (I.C).

\subsection{Information sources \& search strategy}

The following three electronic databases were searched for relevant articles (from inception to March 2020): MEDLINE, (http:/ncbi.nlm.nih.gov/pubmed), Web of Science, (http://isiwebofknowledge.com) and EMBASE (https://www.embase.com/). Based on the PICOs approach, studies that examined temporal changes $(\mathrm{S}=$ study design and $\mathrm{C}=$ comparison $)$ of pain processing $(\mathrm{O}=$ outcome) in patients with WAD ( $\mathrm{P}=$ population), measured with QST (I = Intervention) were included. The search terms are outlined in Table 2 and the complete search strategy is reported in Table S1.

\subsection{Data management}

The following information was systematically summarized in a table of evidence (Table 3), by the first author (J.B.) and checked by the second (D.L.) and third (I.C.) reviewer: (1) author, year of publication and country, (2) study design, (3) characteristics of the study sample, (4) characteristics of the control group if present, (5) outcomes related to QST, (6) moment of testing (baseline/ follow-up), (7) results and (8) remarks. Effect sizes were measured using Hedges' $g$, for all the outcomes of which the required data were provided in the articles (Lakens, 2013; Walter \& Yao, 2007).

TABLE 1 Inclusion and exclusion criteria

\begin{tabular}{|c|c|c|}
\hline & Inclusion & Exclusion \\
\hline Outcome & Quantitative Sensory Testing measurements & Not describing one of the outcome measurements \\
\hline Study design & $\begin{array}{l}\text { Longitudinal studies, cohort studies, prospective studies, } \\
\text { comparative studies, follow up studies, RCT's that } \\
\text { have a waiting list group }\end{array}$ & $\begin{array}{l}\text { Not describing temporal changes, influence of any } \\
\text { kind of treatment, meta-analysis, systematic } \\
\text { review, review }\end{array}$ \\
\hline
\end{tabular}

TABLE 2 Search terms

\begin{tabular}{|c|c|c|c|}
\hline Whiplash population & QST measurements & Pain processing & Temporal changes \\
\hline
\end{tabular}


TABLE 3 Table of evidence

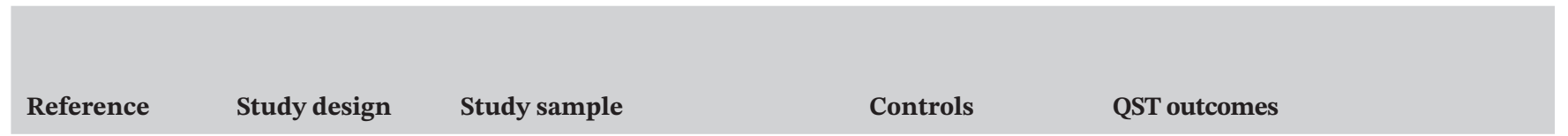

Cluster 1: Longitudinal studies of patients with acute WAD

$\begin{array}{ccc}\text { Chien } & \text { Prospective } & 52 \operatorname{AWAD}\left(32 \%, 200^{*} ; 36.3 \pm\right. \\ \text { et al. (2010), } & \text { longitudinal } & 13.1 \mathrm{y}) \\ \text { Australia } & & \text { Gr1 }=\text { High-risk: } 17 \mathrm{Gr} 2=\text { Low- } \\ & \text { risk: } 35\end{array}$

\begin{tabular}{|c|c|}
\hline $\begin{array}{c}38 \mathrm{HC}\left(289,10 \sigma^{\top}\right. \\
32.6 \pm 8.7 \mathrm{y})\end{array}$ & $\begin{array}{l}\text { Detection thresholds } \\
\text { - cold: dorsal hand } \\
\text { - heat: dorsal hand } \\
\text { - electrical: distal phalanx of index } \\
\text { finger, m. tibialis anterior } \\
\text { - vibration: palmar hand }\end{array}$ \\
\hline
\end{tabular}

$\begin{array}{lcc}\text { Kamper } & \text { Longitudinal } & 100 \mathrm{AWAD}\left(72 \%, 280^{\prime} ; 40.1 \pm\right. \\ \text { et al. (2011), } & \text { cohort } & 13.3 \mathrm{y}) \\ \text { Australia } & & \\ \text { Kasch } & \text { Prospective } & 141 \mathrm{AWAD}\left(749,670^{\prime} ; 35.6 \pm\right. \\ \text { et al. (2001), } & \text { longitudinal } & 10.7 \mathrm{y}) \\ \text { Denmark } & & \end{array}$

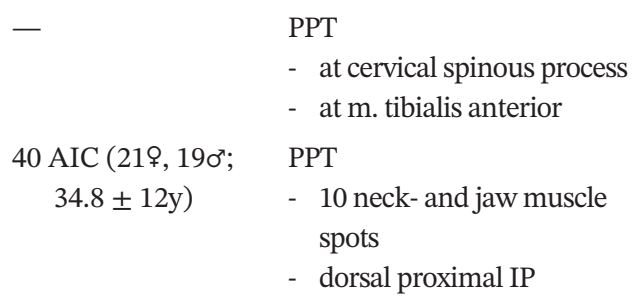

Kasch

et al. (2002),

Prospective longitudinal

$19 \operatorname{AWAD}\left(10 \%, 90^{x} ; 26.3 \pm 4.5 \mathrm{y}\right)$

20 AIC (119, $9 \sigma^{x}$
$25.4 \pm 5.7 y)$

PPT

Denmark

Kasch
et al. (2005),
Denmark
Prospective longitudinal

$141 \operatorname{AWAD}(749,35.0 \pm 10.5 \mathrm{y}$; $\left.67 \sigma^{\circ}, 33.9 \pm 10.5 \mathrm{y}\right)(11$ nonrecovered at $1 \mathrm{y})$

40 AIC

157 AWAD (111우 460'; $37.1 \pm$ 13.8y)

et al. (2008), Longitudinal cohort Denmark

Nebel et al. (2005), Germany
Prospective longitudinal

20 AWAD (119, 90'; $28.75 \pm$ 12.08y)

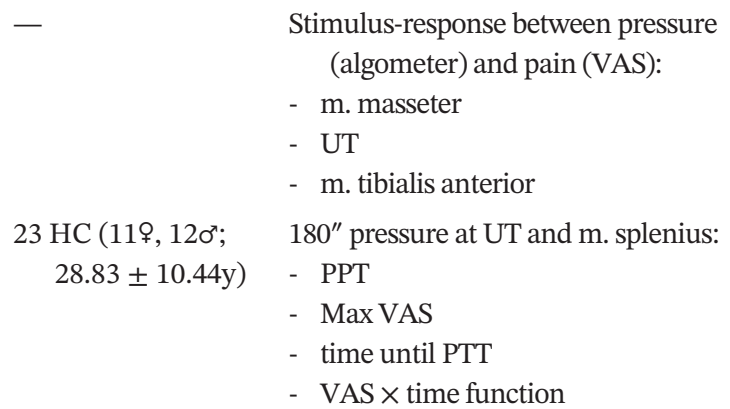

\section{5 | Risk of bias assessment and level of evidence}

The risk of bias of the individual studies was assessed independently by the same two reviewers (J.B. and D.L.). A modified version of the Newcastle-Ottawa
Scale (NOS) was used to make it more appropriate for evaluating the risk of bias accounting for the specific purpose of this review. A detailed description can be found in Table S2. The first topic (selection bias) questions the representativeness and the recruitment. A question was added to verify if the medical history of 


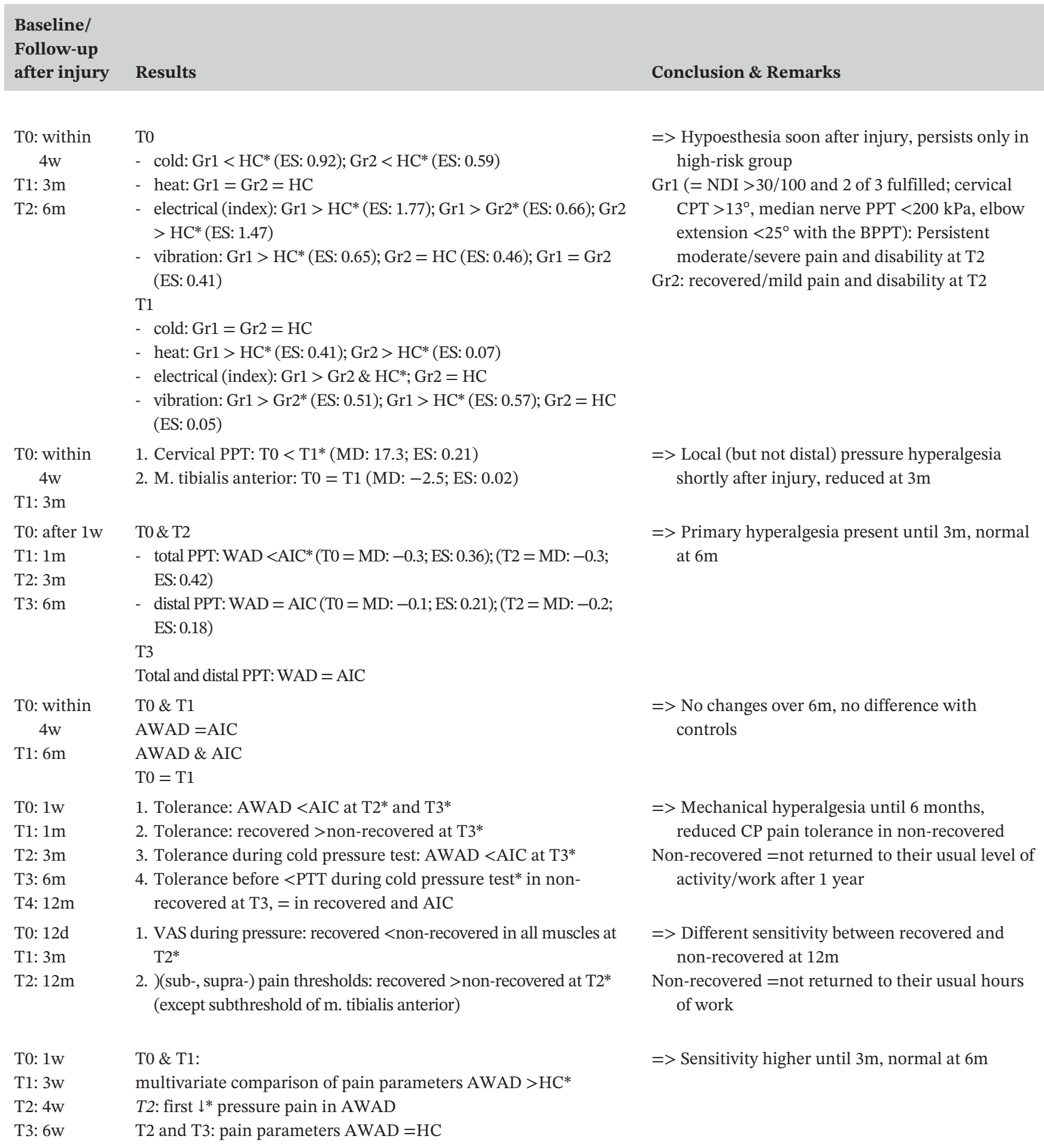

the acute patient group was extensively checked for chronic conditions or previous whiplash injuries. The following adaptations were performed in the second part (comparability bias): (1) age and gender were used as the most important confounding factors, (2) in the case-control studies, the difference between two groups in post-injury period should be at least 3 months and (3) a sample size calculation should have been described and reached. The third section (outcome/exposure bias) was expanded with an extra question about QST, to verify whether a variety of measurements related to pain processing was assessed 
TABLE 3 (Contiuned)

\begin{tabular}{|c|c|c|c|c|}
\hline Reference & Study design & Study sample & Controls & QST outcomes \\
\hline
\end{tabular}

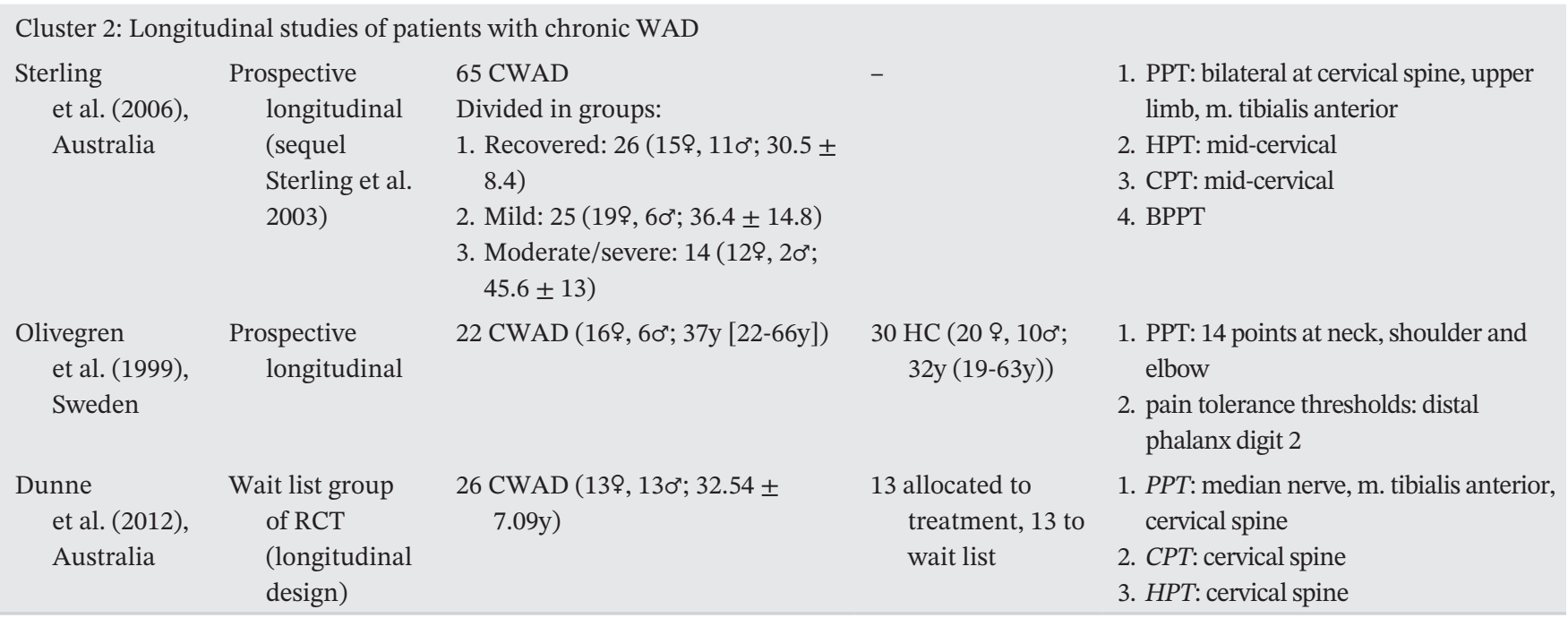

with a reliable and standardized protocol. Questions that were not applicable for the respective study were not assessed (i.e. absence of outcome of interest at the start of the study and ascertainment of exposure). Each study could score a maximum of 10 stars on the modified version of NOS. The methodological quality has also been indicated by a colour; the greener the better the quality. After assessing the methodological quality, a level of evidence was allocated to each included article and a level of conclusion was formulated for every section of the results, according to the Evidence-Based Guideline Development (EBRO) method (Burgers \& van Everdingen, 2004).

\section{RESULTS}

\section{1 | Study selection}

A total of 1704 citations were identified through the selected electronic databases. Screening of references did not result in any additional inclusions. After removing duplicates, $1277 \mathrm{ci}-$ tations remained. These articles were screened based on title and abstract, of which 1248 were found ineligible. The full text screening of 29 potentially relevant studies resulted in 14 eligible articles. Two of them had a cross-sectional design. Whereas longitudinal analyses are favoured over cross-sectional with respect to the aim of this review, we decided to focus only on 


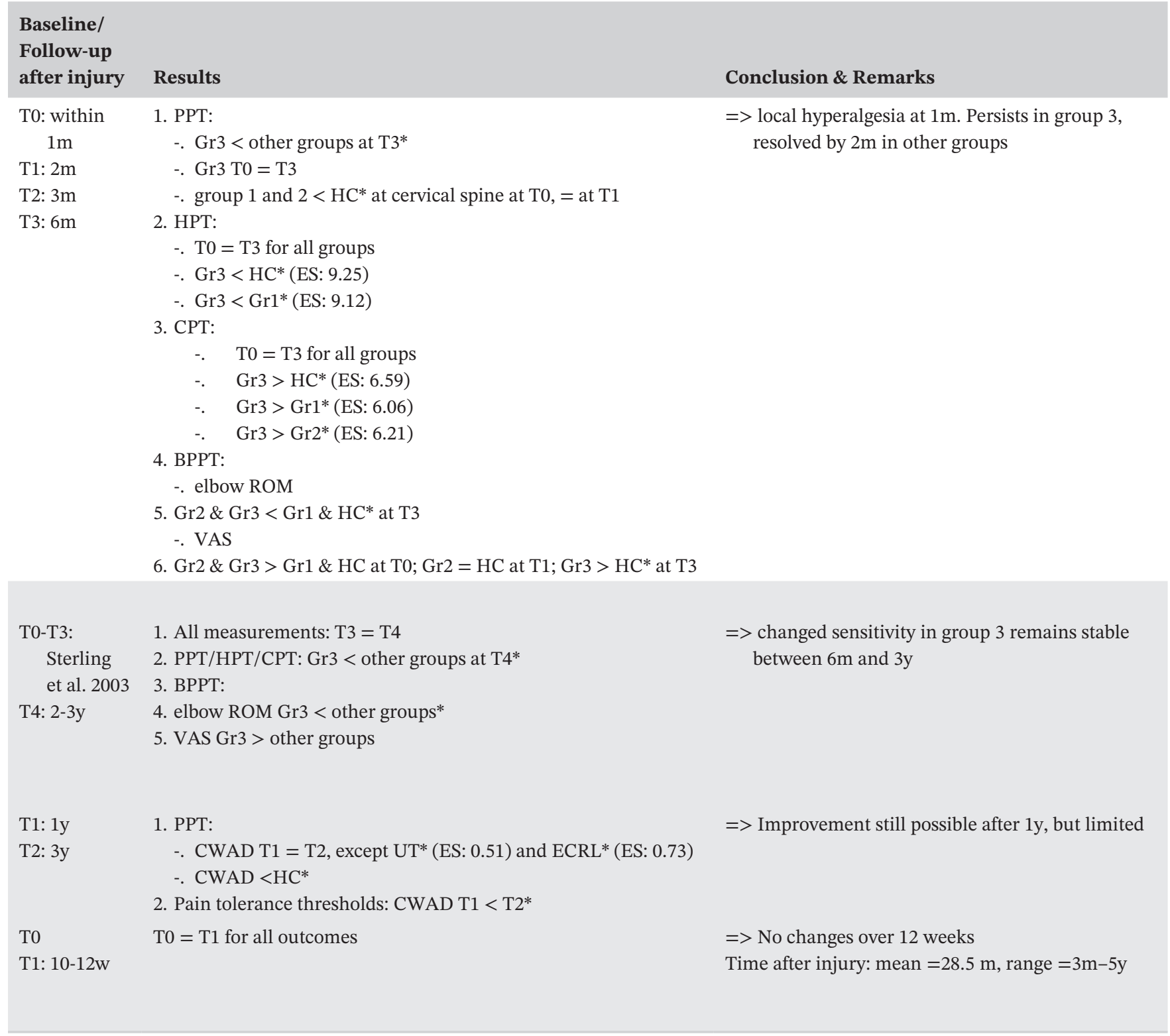

longitudinal data. Accordingly, 12 studies were eventually selected for this systematic review. The specifics of the two crosssectional studies can be found in File S1. An overview of the selection process as well as reasons for exclusion are depicted in Figure 1.

\section{2 | Study characteristics}

The 12 included studies provide data of 838 patients with WAD and 233 controls. Based on the Quebec Task Force Classification (Hartling et al., 2001), three studies included patients with WAD grade I-III (Daenen et al.,
2014; De Kooning et al., 2015; Dunne et al., 2012; Kamper et al., 2011; Olivegren et al., 1999), one study with grade I-II (Nebel et al., 2005), three studies with grade II-III (Sterling, 2010; Sterling et al., 2003, 2006) and one study with grade II (Chien et al., 2010). Four studies (Kasch et al., 2001, 2002, 2005, 2008) did not describe this classification, but also excluded patients in case of fractures or dislocations (i.e. criteria for grade IV). Some studies divided their subjects into groups based on their recovery. Distribution criteria can also be found in Table 3. In this review, the term 'non-recovered' is used for patients who still had moderate to severe pain and disability 6 months after injury. 


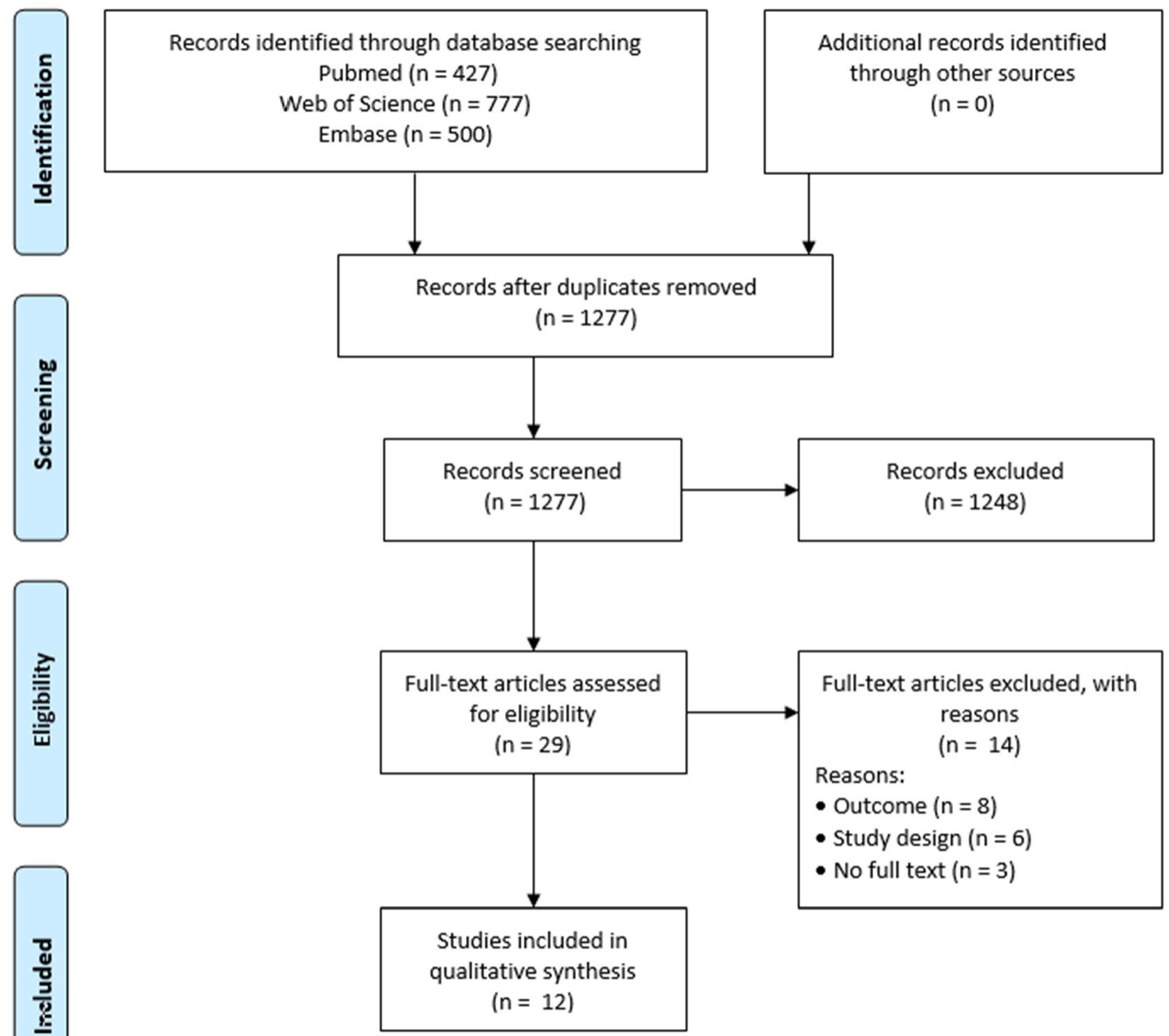

F I G U RE 1 Preferred reporting items for systematic reviews and meta-analyses flow diagram

This review covers data of assessments starting from the first week up to 3 years after whiplash injury. First, five studies (Chien et al., 2010; Nebel et al., 2005; Olivegren et al., 1999; Sterling, 2010; Sterling et al., 2003) followed patients with acute WAD and compared them with healthy controls. Second, three studies (Kasch et al., 2001, 2002, 2005) followed acute patients as well, but compared them with another acute pain population. Third, three studies reported no comparative data but followed a cohort of patients with WAD (Kamper et al., 2011; Kasch et al., 2008; Sterling et al., 2006). And last, one randomized controlled trial (RCT) compared baseline and follow-up data of a waitlist group of patients with chronic WAD (Dunne et al., 2012). A considerable amount of the included studies was published by just two research groups (i.e. Sterling et al. and Kasch et al.). However, with the exception of one study (Sterling et al., 2006) that was the continuation of a previous study (Sterling et al., 2003), they all describe data of a new sample.

All studies, except Chien et al. (2010), measured sensitivity for pressure by algometry. Five studies measured thermal pain thresholds (Chien et al., 2010; Dunne et al., 2012; Sterling, 2010; Sterling et al., 2003, 2006) and only one examined electrical pain thresholds (Chien et al., 2010). The studies by Sterling et al. also included BPPT (Sterling et al., 2003, 2006) or NFR (Sterling, 2010). During the BPPT, mechanical 
TAB L E 4 Methodological quality

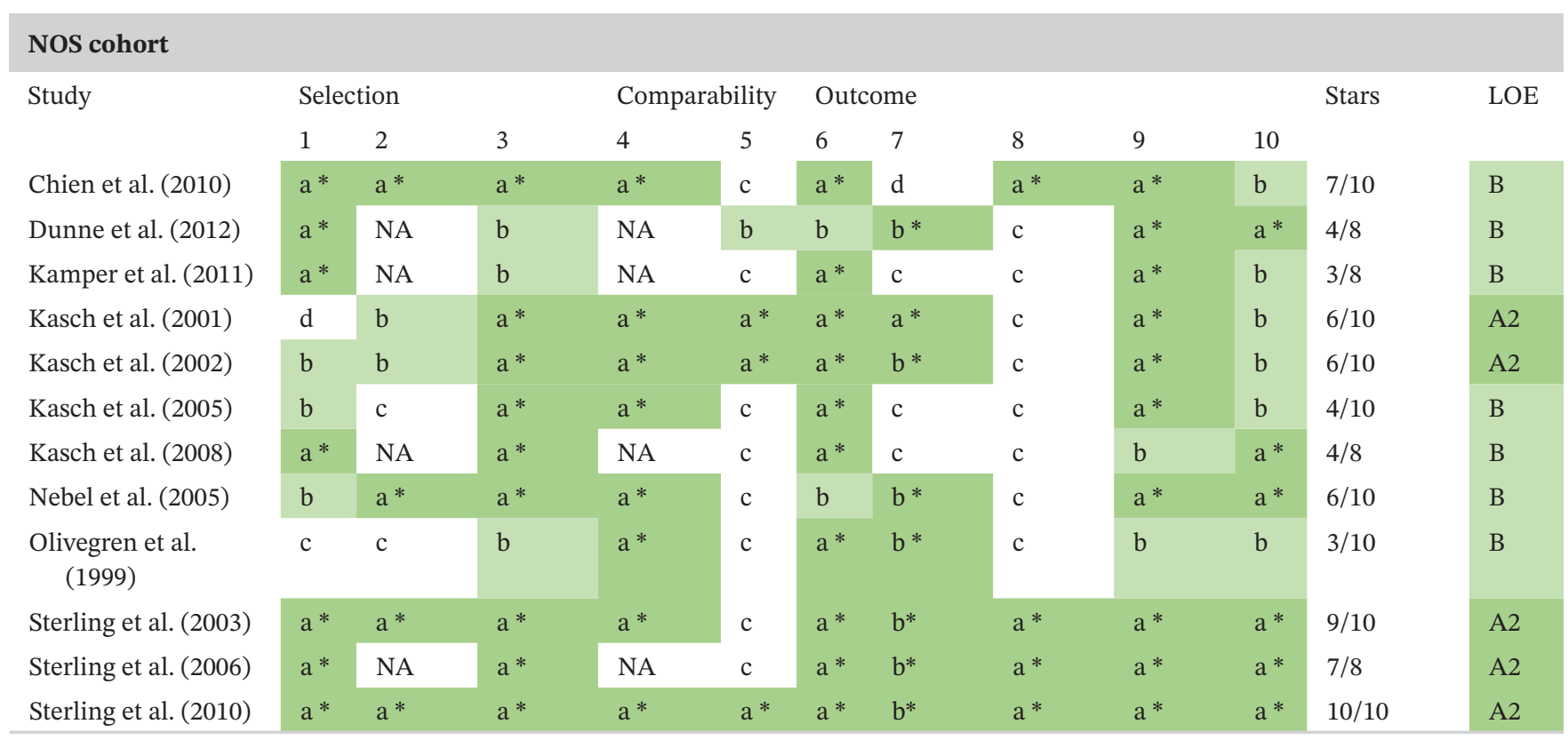

$1=$ case definition; $2=$ selection of controls; $3=$ ascertainment of WAD-related complaints; $4=$ comparability; $5=$ sample size; $6=$ duration of follow-up; $7=$ lost to follow-up; 8 = blind assessment; 9 = description of QST protocol; $10=$ reliability of QST protocol; LOE = level of evidence; NA = not applicable; $\mathrm{a}=$ full accordance to the requirements/minimal risk of bias; $\mathrm{b}=$ requirements not completely met/possible risk of bias; $\mathrm{c}=$ requirements not met/strong risk of bias; $\mathrm{d}=$ no statement; ${ }^{*}=$ NOS star.

sensitivity of the plexus brachialis is assessed by controlled longitudinal provocation, whilst scoring range of motion, protective muscle activity and reproduction of pain (Sterling et al., 2002). NFR thresholds are determined by measuring the lowest intensity of sural nerve electrical stimulation to release a reflex motor response in the biceps femoris (Lim et al., 2011). Conditioned pain modulation (CPM), described as an evaluation of the endogenous pain inhibitory pathway by combining a painful conditioning stimulus with a painful test stimulus (Yarnitsky et al., 2010), was only described in one studies (Kasch et al., 2005). Unfortunately, temporal summation, an increased pain reaction that occurs when repetitive noxious stimulation is applied to the skin more often than once every $3 \mathrm{~s}$ (Price et al., 1977), was not described by one of the included studies.

\section{3 | Risk of bias and level of evidence}

Risk of bias and level of evidence of the included studies are presented in Table 4. An agreement of $86 \%$ on methodological quality (121/140 items) was achieved between both reviewers (J.B. and D.L). In general, the included studies scored moderate to good. The most prominent source of risk of bias was the lack of sample size calculation. Only three studies reported an a priori sample size calculation and adhered to this sample size (Kasch et al., 2001, 2002;
Sterling, 2010). Another item causing increased risk of bias, was the blinding of the assessors for previous results and medical history. This was described in only four articles (Chien et al., 2010; Sterling, 2010; Sterling et al., 2003, 2006). All but three studies (Dunne et al., 2012; Kamper et al., 2011; Olivegren et al., 1999) that included patients with acute WAD, screened for previous whiplash traumas and chronic pain conditions. All studies that involved controls justified comparability for age and gender. Only two longitudinal studies had a follow-up period of less than 3 months (Dunne et al., 2012; Nebel et al., 2005). Finally, the QST protocol was well described in the majority of the studies (with the exception for Kasch et al., 2008; Olivegren et al., 1999), but only 6 of the 12 included studies used a validated protocol (Daenen et al., 2014; De Kooning et al., 2015; Dunne et al., 2012; Kasch et al., 2008; Nebel et al., 2005; Sterling, 2010; Sterling et al., 2003, 2006).

Regarding the level of evidence, the reviewers agreed about 10 of the 12 studies (86\%). After deliberation, six studies were classified as level A2 and six studies as level B.

\section{4 | RESULTS OF INDIVIDUAL STUDIES-SYNTHESIS OF RESULTS}

With the intention to divide results into central changes during the acute and during the chronic phase, studies were allocated to one of the following two clusters: (1) 
.

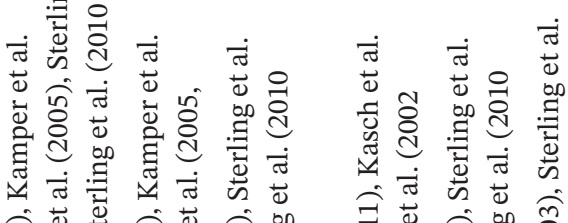

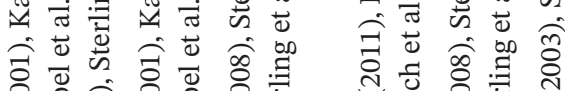

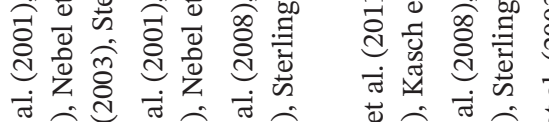

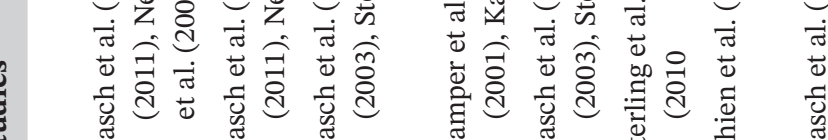

I

to.

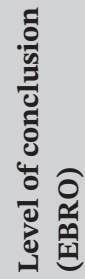

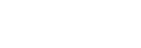

$\Xi$
$\frac{0}{2}$
$\frac{2}{0}$
ป

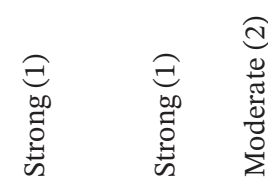

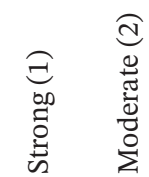

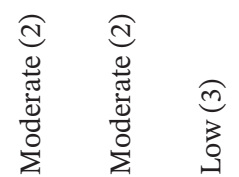

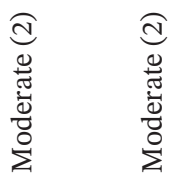

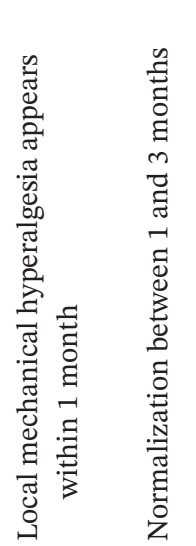

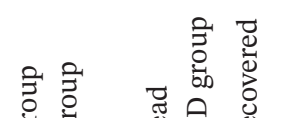

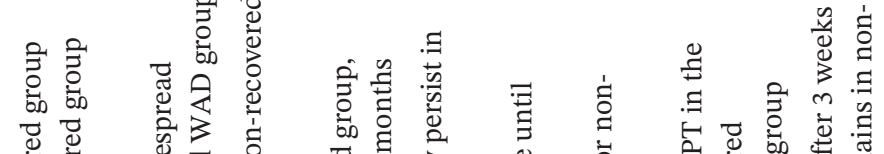

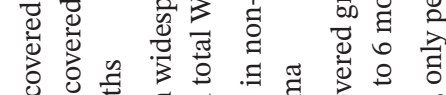

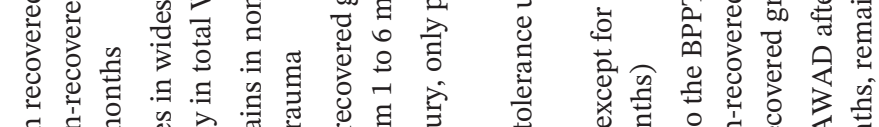

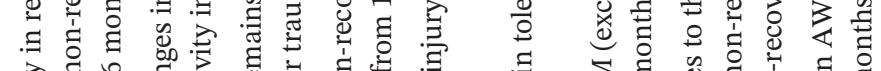

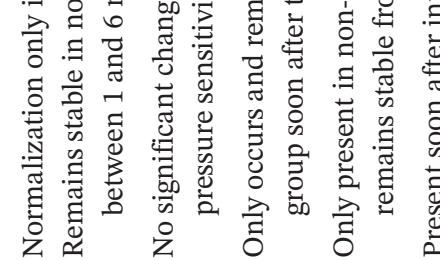

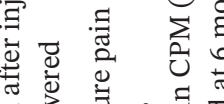
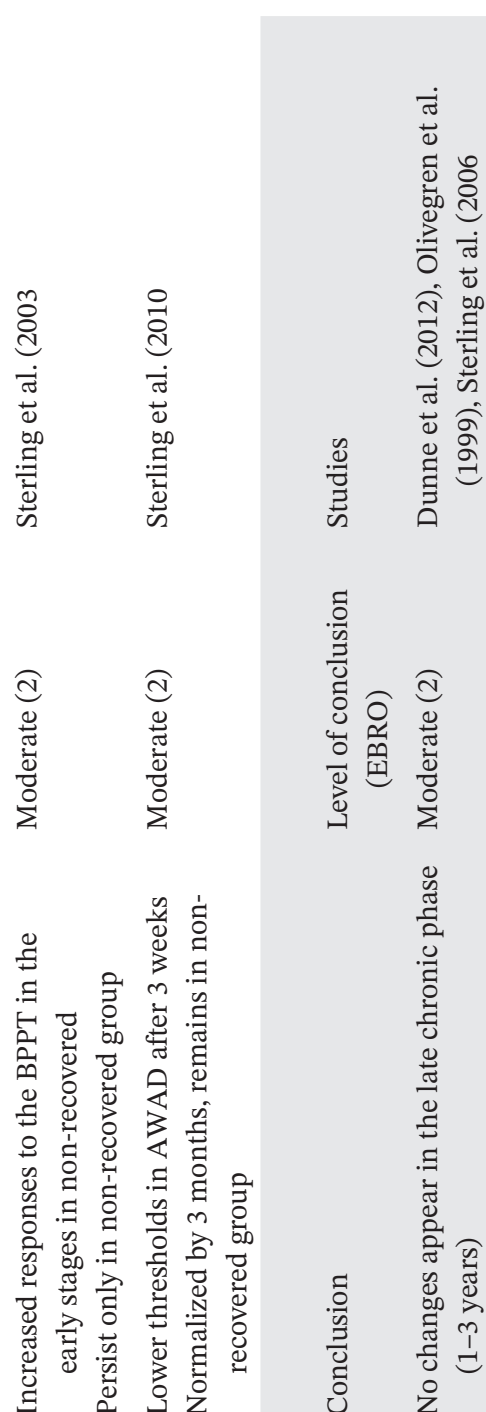

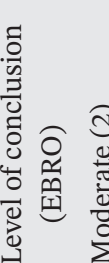

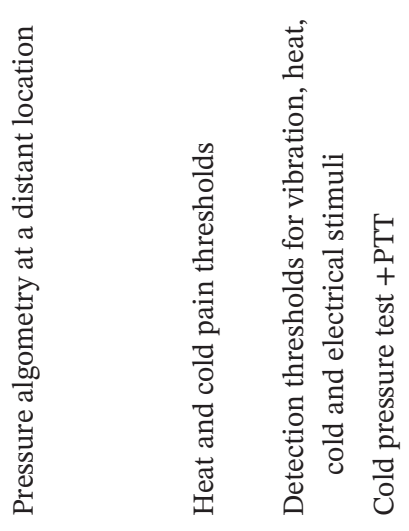

总产

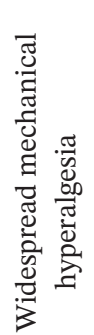

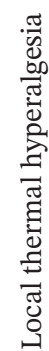

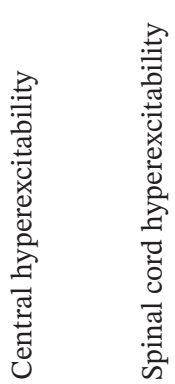


longitudinal studies of patients with acute WAD, (2) longitudinal studies of patients with chronic WAD (Table 5).

\section{1 | Longitudinal studies of patients with acute WAD}

The first cluster comprised nine studies starting with baseline testing within the first 4 weeks after whiplash injury (Chien et al., 2010; Kamper et al., 2011; Kasch et al., 2001, 2002, 2005, 2008; Nebel et al., 2005; Sterling, 2010; Sterling et al., 2003).

\subsection{Mechanical hyperalgesia}

Sensitivity for pressure was the most commonly measured outcome in these studies. Six studies described pressure algometry at a local area (neck or shoulders), reflecting local mechanical hyperalgesia (Kamper et al., 2011; Kasch et al., 2001, 2008; Nebel et al., 2005; Sterling, 2010; Sterling et al., 2003). Five of these studies concluded that sensitivity for pressure is increased in the first month after whiplash injury, when comparing with a control group (Kamper et al., 2011; Kasch et al., 2001; Nebel et al., 2005; Sterling, 2010; Sterling et al., 2003). These findings normalized after 4 weeks (Nebel et al., 2005), 3 months (Kamper et al., 2011) or 6 months (Kasch et al., 2001). Two studies by Sterling et al. (Sterling, 2010; Sterling et al., 2003) found that the development of mechanical hyperalgesia was influenced by recovery. Pressure pain thresholds (PPTs) of patients who were fully recovered or had only mild pain and disability (Neck Disability Index [NDI] score <28\%) after 6 months were no longer different from controls after 2 months (Sterling et al., 2003). In contrast, patients who developed moderate to severe pain-related disability (NDI score $>30 \%$ ) persistently showed lower PPTs. The divided outcome depending on the extent of recovery can be supported by Kasch et al. (2008), who concluded that hypersensitivity for pressure only remained in non-recovered patients.

To conclude, there is strong evidence for local mechanical hyperalgesia within the first month after whiplash injury (level of conclusion 1). Overall, these findings normalize within the first 3-6 months post-injury. However, only recovered patients show these normalizations. Local mechanical hyperalgesia remains stable from 1 to 6 months in non-recovered patients (level of conclusion 2).

Six studies included pressure measurements at a remote non-injured area, reflecting widespread mechanical hyperalgesia (Kamper et al., 2011; Kasch et al., 2001, 2002, 2008; Sterling, 2010; Sterling et al., 2003). The studies by Kasch et al. (2001) and Kasch et al. (2002) reported that PPTs at an asymptomatic location were similar across patients with WAD and ankle-injured controls. Additionally, Kamper et al. (2011) found no changes in distal PPTs shortly after injury compared to 3 months later. Studies that divided patients based on recovery found that only the non-recovered group showed lower PPTs at distal locations, compared to healthy controls (Sterling, 2010; Sterling et al., 2003). These findings occurred from the first assessment (at 3 weeks) and remained during all examinations (until 6 months' post-injury). Furthermore, another study by Kasch et al. (2008) noted lower distal PPTs in non-recovered compared to recovered patients at 12 months.

In summary, there is strong evidence that widespread mechanical hyperalgesia does not occur at any stage in the total WAD group (level of conclusion 1). It is likely that widespread hyperalgesia for pressure is only present in non-recovered patients, appearing soon after injury and remaining stable through the following stages (level of conclusion 2).

\subsection{Thermal hyperalgesia}

Only two studies utilized thermal measurements (Sterling, 2010; Sterling et al., 2003). These studies showed lower heat (Sterling et al., 2003) and higher cold pain thresholds (Sterling, 2010; Sterling et al., 2003) at the cervical spine in non-recovered patients compared to healthy controls and recovered patients, from the first month until 6 months post-injury. Unfortunately, no studies measured thermal hyperalgesia at a remote location.

There is moderate evidence that local hyperalgesia for thermal stimuli only occurs in the non-recovered group and is present from the early post-injury phase until at least 6 months (level of conclusion 2).

\section{4 | Sensory hypoesthesia}

Chien et al. (2010) examined sensory detection thresholds at the hand. Cold detection thresholds were lower in patients with WAD than in healthy controls in the first month, but normalized within 3 months. No difference was found in heat detection thresholds between patients with acute WAD and controls. Elevated heat detection thresholds were solely seen in non-recovered patients at 3 and 6 months. In the first month, electrical detection thresholds were higher in all patients with acute WAD than in controls. At 3 and 6 months, only electrical detection thresholds from non-recovered patients still differed from controls. Vibration detection thresholds were significantly higher in non-recovered patients than in healthy controls, but not in the total or recovered group.

Although only one study measured detection thresholds, there is evidence of moderate quality that supports the presence of hypoesthesia soon after injury, which 
persists predominantly in non-recovered patients (level of conclusion 3).

\section{5 $\quad$ Pain tolerance}

Kasch et al. (2005) found lower pressure pain tolerance thresholds in patients with WAD compared to ankleinjured controls after 3 and 6 months, but not after 12 months. A reduction in cold pressure pain endurance was solely seen in non-recovered patients and was present immediately after injury.

To conclude, pain tolerance seems to be reduced during the first 6 months and is likely to persist only in non-recovered patients (level of conclusion 3).

\subsection{Conditioned pain modulation}

Evaluation of the endogenous pain inhibition mechanisms by adding a painful conditioning stimulus to the test stimulus, was only performed by Kasch et al. (2005). Pressure pain tolerance thresholds during immersion of the hand in cold water were significantly reduced in patients with WAD compared to controls at 6 months, but not at 3 and 12 months. These thresholds were also lower in non-recovered patients than in recovered patients at 6 months. Comparing pain tolerance before and after the cold water immersion, to asses CPM responses, showed no differences in controls and patients, except for nonrecovered patients at 6 months.

No strong conclusion could be made about endogenous pain modulation, as this study failed to demonstrate a significant CPM effect in patients or controls.

\subsection{Brachial plexus provocation test}

Sterling et al. (2003) reported lower elbow range of motion and higher VAS-scores in the non-recovered group than in the recovered and control group in the first month. Although the recovered group showed similar results on the BPPT as controls after 2 months, the non-recovered group showed no change over time.

These findings suggest altered BPPT, starting from the early stage, in patients who do not recover (level of conclusion 2).

\section{8 $\quad$ Nociceptive flexion reflex}

The NFR following electrical stimulation to the sural nerve at the ankle was measured by electromyography (EMG) at the biceps femoris muscle, in the study by Sterling (2010). Three weeks after injury, whiplash patients showed lower NFR thresholds than controls. At 3 and 6 months, the difference persisted only in the non-recovered group.

Although evidence is limited to one study, there is moderate evidence for spinal cord hyperexcitability, measured by NFR, soon after whiplash injury and is only persisting in non-recovered patients (level of conclusion 2).

\section{9 | Longitudinal studies of patients with chronic WAD}

A second cluster was made for longitudinal studies assessing patients with chronic WAD at two different moments, in order to reach conclusions on temporal changes in the chronic stage. The study by Olivegren et al. (1999) found no differences in PPTs between assessments at 1 and 3 years after injury at 12 of the 14 locations, albeit increased PPTs at the trapezius muscle and extensor carpi radialis longus. With the exception of a remarkable increase in pain tolerance level, this study implies improvement in the chronic stage is limited. The study by Sterling et al. (2006) was a continuation of their study in 2003 (Sterling et al., 2003) with an assessment after 2-3 years. By measuring BPPT, local and distal PPTs and mid-cervical heat and cold pain thresholds, they found no differences between the 6 month' and the 3 years' assessment. Only the results of the nonrecovered group remained different from healthy controls. The RCT by Dunne et al. (2012) was considered as a longitudinal study, as only the results of the control intervention group were extracted. This rather small group of patients with chronic WAD was examined two times with an interval of 12 weeks. No differences across time points were established in local and distal PPTs or local heat or cold pain thresholds.

To conclude, there is moderate evidence that impaired sensory function is present in the chronic phase and is likely to maintain during the late chronic phase (level of conclusion 2). However, minor improvements are possible.

\section{$5 \mid$ DISCUSSION}

To our knowledge, this is the first systematic review to summarize changes in QST outcomes from the acute until the late chronic phase in patients with chronic WAD grade I-III, based on the Quebec Task Force Classification (Hartling et al., 2001). In general, results show adaptations in the nociceptive pathways. These changes occur within the first month and seem to normalize within 3 months 
in most patients. This normalization follows the principles and timeline of normal soft-tissue repair (Järvinen et al., 2014). However, in patients who eventually develop chronic complaints, the somatosensory function remains disturbed for years.

Several reviews have focussed on altered pain processing in the acute or the chronic phase separately, but not combined (Curatolo et al., 2004; Marcuzzi et al., 2015; Van Oosterwijck et al., 2013). In addition, many studies examined recovery after whiplash, but the great majority only used questionnaires and were restricted to self-reported parameters (Al-Khazali et al., 2020; Kamper et al., 2008). In contrast, QST has the advantage to be semi-objective, combining physiological and psychological factors to evaluate the mechanisms underlying the pain experience. Those mechanisms do not necessarily correlate with subjective symptoms and are implicated in the transition from acute to chronic pain (Uddin \& MacDermid, 2016).

Three static (i.e. targeting pain thresholds) and three dynamic (i.e. CPM, BPPT and NFR) QST measures were described:

First, strong evidence was found for mechanical hyperalgesia in symptomatic areas within the first month. These impairments normalized within 3 months. Patients who did not recover remained mechanical hypersensitive during all post-injury phases. This dovetails with a systematic review that reports recovery of most patients in the initial 3 months and limited improvements beyond this point (Kamper et al., 2008). Furthermore, mechanical sensitivity in patients with WAD differed only from controls when measured at local areas. This suggests that local mechanical hyperalgesia occurs in the acute phase, but generally widespread mechanical hyperalgesia does not. Hyperalgesia at asymptomatic areas was only found in patients who eventually developed chronic pain. Hence, the non-recovered subgroup tends to show signs of adaptations of the central nervous system soon after injury. The crucial role of central sensitization in the persistence of pain complaints (Van Oosterwijck et al., 2013) indicates the high risk of chronicity in patients with initial widespread mechanical hyperalgesia. Pressure algometry is a reliable tool to assess mechanical hyperalgesia in patients with chronic neck pain (Jorgensen et al., 2014; Prushansky et al., 2007) and healthy persons (Cathcart \& Pritchard, 2006). However, caution is needed when interpreting widespread hyperalgesia as a central adaptation, as peripheral involvement cannot be completely excluded.

Second, thermal pain thresholds are commonly used in QST and have shown good reproducibility (Heldestad et al., 2010; Wasner \& Brock, 2008). They are strongly correlated with pressure and electrical pain thresholds (Neddermeyer et al., 2008), but have additional value in identifying high-risk patients. Especially the presence of cold hyperalgesia is predictive for poor outcome after whiplash injury (Sterling et al., 2005). The results of this review also suggest that sensitivity for thermal stimuli follows the same pattern as mechanical sensitivity. Thermal hyperalgesia occurs within the first month, but only in the group that developed moderate to severe symptoms. Unfortunately, thermal thresholds were only measured at the cervical spine and consequently no statement could be made about widespread thermal hyperalgesia. However, previous studies described thermal hyperalgesia at remote areas in chronic WAD (Van Oosterwijck et al., 2013), as well as in other chronic conditions such as knee osteoarthritis (Moss et al., 2016), chronic myofascial temporomandibular disorder (Fernandez-de-las-Penas et al., 2010) and chronic low back pain (Hübscher et al., 2014).

Third, sensory detection thresholds were only described in one study (Chien et al., 2010), but correspond with previous findings in acute and chronic WAD (Chien et al., 2008, 2009). Evidence was provided for hypoesthesia soon after injury in non-recovered patients. This indicates that central facilitatory, as well as inhibitory processes, are early affected in this subgroup. Patients with chronic pain often report numbness in the painful area, even in the absence of structural peripheral or central nerve lesion (Geber et al., 2008; Moriwaki \& Yuge, 1999). This sensory decline in clinical pain conditions has also been shown by experimentally induced pain in healthy individuals, supporting that pain-induced somatosensory plasticity induces hypoesthesia and hyperalgesia (Geber et al., 2008; Magerl \& Treede, 2004). Both are caused by altered processing by neurons in the central nervous system, leading to central inhibition of non-painful processing (Moriwaki \& Yuge, 1999). However, remarkably different brain processing is involved in hypoesthesia than in hyperalgesia (Stammler et al., 2008).

Fourth, few studies executed dynamic QST methods. Results of the BPPT, CPM and NFR measurements suggest early changes in central hyperexcitability as well as dysfunctional pain inhibition in the group of non-recovered patients. Notwithstanding the importance of evaluating the level of excitability or inhibition, the knowledge on temporal changes of dynamic QST measurements remains inconclusive.

Moderate evidence was found that improvements in pain and disability as well as in QST outcomes stagnate after 3 months. This highlights the need for early detection and treatment of high-risk patients. As QST measurements especially showed to be altered in patients that eventually develop chronic complaints, there might be a prognostic role for QST in clinical practice. A lot of prognostic factors have been previously demonstrated, that is, cold hyperalgesia (Goldsmith et al., 2012), general psychological distress (Kamper et al., 2008), age and gender (Cote et al., 2001; 
Walton et al., 2013). Yet, these findings are inconsistent. Only high initial neck pain and disability are widely accepted as a prognostic factor for chronic complaints (Sarrami et al., 2017; Scholten-Peeters et al., 2003). Notwithstanding the potential added value of these prognostic factors, understanding the processes involved in chronification is essential to decrease the prevalence of chronic pain conditions. Nevertheless, the presence of altered sensory function in high-risk patients in the earliest tests arises the question if there was not already a difference in pain processing before the trauma. Some patients are possibly predisposed to develop chronic pain due to an already impaired somatosensory system before the injury. Also, genetic variants can induce predisposition to chronic pain (Zorina-Lichtenwalter et al., 2016). This argumentation could also explain why high initial pain is such an important prognostic factor. But of course, it is not feasible to assess patients before their accident. This only strengthens the need for early screening in order to provide appropriate mechanism-based management strategies in the acute stage.

Previous studies provided evidence that due to adaptations of neurons in the central nervous system, the pain is no longer corresponding with the presence, intensity or duration of noxious peripheral stimuli (Latremoliere \& Woolf, 2009; Uddin \& MacDermid, 2016). Moreover, peripheral nociceptive input might even not be required to provoke pain hypersensitivity (Harte et al., 2018; Woolf, 2011). On the other hand, some studies show that central adaptations depend on the presence of nociceptive input (Curatolo, 2011; Herren-Gerber et al., 2004). In $60 \%$ of the patients with chronic WAD, the zygapophysial joints are a source of pain (Lord et al., 1996) and selective nerve blocks in the cervical spine decreases sensory hypersensitivity (Schneider et al., 2010). Based on an MRI study, unhealed ligaments in the upper cervical spine in patients with chronic WAD are associated with pain and disability (Kaale et al., 2005). Furthermore, neuroinflammation in the peripheral and central nervous system may be involved in the development of central sensitisation (Ji et al., 2018). This could also be an explanation for the sensory changes, as systematic inflammation was found to contribute to the chronification of WAD (Farrell et al., 2020). The altered response to stimuli can also be caused by lesions or diseases of the somatosensory nervous system, as seen in neuropathic pain mechanisms (Baron et al., 2017; Merskey, 1994). Patients with WAD can show local hypersensitivity due to peripheral nerve damage, muscle tension or cervical malposition. Widespread hypersensitivity can, however, not be unilaterally explained by peripheral lesions. Their pain mechanism is therefore often described as 'nociplastic pain' (Kosek et al., 2021), which is defined by The International Association for the Study of Pain (IASP) as pain that arises from altered nociception despite no clear evidence of actual or threatened tissue damage causing the activation of peripheral nociceptors or threatened tissue damage causing the activation (Kosek et al., 2016). However, there are many similarities in underlying mechanisms of sensitization between neuropathic and musculoskeletal chronic pain conditions (Arendt-Nielsen \& Graven-Nielsen, 2011). Involvement of peripheral nerve tissue in the changed sensitivity cannot be excluded. Previous research showed that $34 \%$ of patients with acute WAD demonstrate predominantly neuropathic pain (Sterling \& Pedler, 2009). In addition, a mix of pain mechanisms is frequently seen in patients with chronic pain. The level of certainty that a patient's pain is neuropathic in nature can be evaluated by the neuropathic pain grading system (Finnerup et al., 2016), which is taking into account the history of neurological lesions, pain distribution, clinical examination and diagnostic tests. Identifying the patient's pain mechanism, based on the clinical pattern and the presence of detectable nerve or tissue damage, could help guide the rehabilitation approach (Nijs et al., 2016) and could also shed more light on the extent to which such mechanisms contribute to alterations in pain processing.

It is nevertheless possible that QST outcomes are altered as a consequence of pain, disability or psychosocial factors. That could explain why they only normalize in patients without persisting pain. Hence, it remains unclear whether ongoing nociceptive input is necessary for central sensitization. This makes it difficult for clinicians to decide to focus more on affecting peripheral input or on central changes and psychological distress. Patients with WAD often experience psychological distress, for instance caused by anxiety, depression, compensation claim lodgement or post-traumatic stress symptoms (Andersen et al., 2011; Sterling et al., 2010). Psychological factors are even found to be predictors of poor outcome (Sterling et al., 2006). Abnormalities in stress-regulating systems have also been demonstrated after whiplash injury (Gaab et al., 2005). Even in the absence of tissue injury, stress can alter pain sensitivity and induce allodynia and hyperalgesia (Crettaz et al., 2013; McLean, 1976; Olango \& Finn, 2014). This may indicate that stress plays a major role in the maintenance of hypersensitivity, which this review shows to be present in non-recovered patients. The results of psychological questionnaires were consistent with the QST findings; higher scores compared to healthy controls were seen in the acute phase, whereas after 3-6 months the recovered patients showed improvements and the non-recovered patients did not (Chien et al., 2010; Sterling et al., 2003, 2006). Targeting psychological factors has been found an efficacious part of treatment in acute and chronic WAD (Dunne et al., 2012; Sterling et al., 2019). 
As pain hypersensitivity is considered a prognostic indicator for poor outcome in musculoskeletal pain (Georgopoulos et al., 2019), quantifying pain processing is of paramount importance in identifying high-risk patients and adjusting suitable treatment strategies. QST might be a feasible and effective tool, to be combined with selfreported questionnaires and clinical examination. The German Research Network on Neuropathic Pain (DFNS) has developed a valid laboratory-based QST protocol and offers a reference database of healthy individuals and patients with neuropathic pain syndromes (Rolke et al., 2006; Vollert et al., 2015). However, the high costs, specific equipment and required amount of time of laboratorybased QST obstruct the clinical application. Bed-site QST could be an attainable alternative. These protocols allow clinicians to easily and cheaply asses somatosensory abnormalities. Bed-site QST has recently shown to be correlated with laboratory-based QST (Koulouris et al., 2020; Reimer et al., 2020). However, a standardized bed-site QST protocol and normative data for chronic musculoskeletal pain populations should be available to identify sensory phenotypes, which may guide therapeutic interventions. Given the fact that chronic pain after whiplash injury is a complex condition and spontaneous improvements are infrequent, rehabilitation should focus on the early phase in order to prevent chronification.

\section{1 | Strengths and limitations}

Combining different aspects of QST is one of the strengths of this review. Focussing on QST outcomes, instead of on self-reported pain intensity, provides a more clear and thorough answer to the study aim and has been less investigated. Moreover, by making an overview of the findings of altered pain processing in all post-injury phases, conclusions can be made about the development of these disturbances in the sensory function. Nevertheless, the present review was confronted with some contextual limitations. First, the heterogeneity in QST protocols and follow-up timelines made it hard to cluster specific results. Second, few studies used dynamic QST measurements, which made it impossible to make strong conclusions about pain excitability or inhibition. This is regrettable, because these tests can evaluate important characteristics of the pain system. Third, most studies only measured at local areas, restricting the findings regarding widespread hyperalgesia. Fourth and final, the use of medical or physical treatment during the study duration was seldom reported. This information could influence the interpretation of the results.

Future research should target to develop a standardized (bed-site) QST protocol and collect normative data which could, in relation with self-reported pain parameters, allow clinicians to identify the risk for chronification. In order to draw stronger conclusions about central changes, multiple QST outcomes and assessments of brain alternations should be combined. There is a need for more insights on why some patients are predisposed to develop chronic pain, how to identify patients with high risk in a clinical setting and the best way to approach the patients who are already in the chronic phase.

\section{6 | CONCLUSION}

Based on QST, changes in pain processing occur soon after whiplash injury and normalize within 3 months in most individuals. Already in the early phase, differences can be observed between patients that will recover and those developing chronic pain. These differences are indicative of the predictive value of QST. In the chronic stage, little to no improvements in pain processing were reported. This highlights the need and feasibility for early screening, to help clinicians to identify high-risk patients and adjust appropriate treatment strategies in the acute phase.

\section{CONFLICT OF INTEREST}

The authors declare no conflicts of interest.

\section{AUTHOR CONTRIBUTIONS}

J. Bontinck involved in systematic search of the literature and drafting the manuscript. J. Bontinck, D. Lenoir and I. Coppieters involved in screening for eligibility and assessment of methodological quality of the manuscript. M. Meeus, B. Cagnie, I. Coppieters, I. Timmers, C. Murillo, L. Bernaers and E. Cnockaert carried out the critical revision of manuscript for content and language.

\section{ORCID}

Jente Bontinck (D) https://orcid.org/0000-0002-0983-551X

\section{REFERENCES}

Al-Khazali, H. M., Ashina, H., Iljazi, A., Lipton, R. B., Ashina, M., Ashina, S., \& Schytz, H. W. (2020). Neck pain and headache after whiplash injury: A systematic review and meta-analysis. Pain, 161, 880-888. https://doi.org/10.1097/j.pain.0000000000 001805

Andersen, T. E., Elklit, A., \& Vase, L. (2011). The relationship between chronic whiplash-associated disorder and post-traumatic stress: Attachment-anxiety may be a vulnerability factor. European Journal of Psychotraumatology, 2, 5633. https://doi. org/10.3402/ejpt.v2i0.5633

Arendt-Nielsen, L., \& Graven-Nielsen, T. (2011). Translational musculoskeletal pain research. Best Practice \& Research 
Clinical Rheumatology, 25, 209-226. https://doi.org/10.1016/ j.berh.2010.01.013

Banic, B., Petersen-Felix, S., Andersen, O. K., Radanov, B. P., Villiger, P. M., Arendt-Nielsen, L., \& Curatolo, M. (2004). Evidence for spinal cord hypersensitivity in chronic pain after whiplash injury and in fibromyalgia. Pain, 107, 7-15. https://doi. org/10.1016/j.pain.2003.05.001

Baron, R., Maier, C., Attal, N., Binder, A., Bouhassira, D., Cruccu, G., Finnerup, N. B., Haanpää, M., Hansson, P., Hüllemann, P., Jensen, T. S., Freynhagen, R., Kennedy, J. D., Magerl, W., Mainka, T., Reimer, M., Rice, A. S. C., Segerdahl, M., Serra, J., ... Treede, R. D. (2017). Peripheral neuropathic pain: A mechanism-related organizing principle based on sensory profiles. Pain, 158, 261-272. https://doi.org/10.1097/j.pain.0000000000000753

Boivie, J. (2003). Central pain and the role of quantitative sensory testing (QST) in research and diagnosis. European Journal of Pain, 7, 339-343. https://doi.org/10.1016/S1090-3801(03) 00046-6

Burgers, J. S., \& van Everdingen, J. J. (2004). Evidence-based guideline development in the Netherlands: The EBRO platform. Nederlands Tijdschrift Voor Geneeskunde, 148, 2057-2059.

Cathcart, S., \& Pritchard, D. (2006). Reliability of pain threshold measurement in young adults. The Journal of Headache and Pain, 7, 21-26. https://doi.org/10.1007/s10194-006-0265-7

Chien, A., Eliav, E., \& Sterling, M. (2008). Hypoesthesia occurs in acute whiplash irrespective of pain and disability levels and the presence of sensory hypersensitivity. Clinical Journal of Pain, 24, 759-766. https://doi.org/10.1097/AJP.0b013e3181773b95

Chien, A., Eliav, E., \& Sterling, M. (2009). Hypoaesthesia occurs with sensory hypersensitivity in chronic whiplash-further evidence of a neuropathic condition. Manual Therapy, 14, 138-146. https://doi.org/10.1016/j.math.2007.12.004

Chien, A., Eliav, E., \& Sterling, M. (2010). The development of sensory hypoesthesia after whiplash injury. The Clinical Journal of Pain, 26, 722-728. https://doi.org/10.1097/AJP.0b013e3181 f096ac

Cote, P., Cassidy, J. D., Carroll, L., Frank, J. W., \& Bombardier, C. (2001). A systematic review of the prognosis of acute whiplash and a new conceptual framework to synthesize the literature. Spine, 2001(26), E445-458. https://doi.org/10.1097/00007632200110010-00020

Crettaz, B., Marziniak, M., Willeke, P., Young, P., Hellhammer, D., Stumpf, A., \& Burgmer, M. (2013). Stress-induced allodyniaEvidence of increased pain sensitivity in healthy humans and patients with chronic pain after experimentally induced psychosocial stress. PLoS One, 8, e69460. https://doi.org/10.1371/ journal.pone.0069460

Curatolo, M. (2011). Diagnosis of altered central pain processing. Spine, 36, S200-S204. https://doi.org/10.1097/BRS.0b013e3182 $387 \mathrm{f} 3 \mathrm{~d}$

Curatolo, M., Arendt-Nielsen, L., \& Petersen-Felix, S. (2004). Evidence, mechanisms, and clinical implications of central hypersensitivity in chronic pain after whiplash injury. Clinical Journal of Pain, 20, 469-476. https://doi.org/10.1097/00002508200411000-00013

Daenen, L., Nijs, J., Cras, P., Wouters, K., \& Roussel, N. (2014). Changes in pain modulation occur soon after Whiplash trauma but are not related to altered perception of distorted visual feedback. Pain Practice, 14, 588-598. https://doi.org/10.1111/ papr.12113
De Kooning, M., Daenen, L., Roussel, N., Cras, P., Buyl, R., Ickmans, K., Struyf, F., \& Nijs, J. (2015). Endogenous pain inhibition is unrelated to autonomic responses in acute whiplash-associated disorders. Journal of Rehabilitation Research and Development, 52, 431-440. https://doi.org/10.1682/JRRD.2014.06.0154

Dunne, R. L., Kenardy, J., \& Sterling, M. (2012). A randomized controlled trial of cognitive-behavioral therapy for the treatment of PTSD in the context of chronic whiplash. Clinical Journal of Pain, 28, 755-765. https://doi.org/10.1097/AJP.0b013e318243e16b

Farrell, S. F., de Zoete, R. M. J., Cabot, P. J., \& Sterling, M. (2020). Systemic inflammatory markers in neck pain: A systematic review with meta-analysis. European Journal of Pain, 24, 16661686. https://doi.org/10.1002/ejp.1630

Fernandez-de-las-Penas, C., Galan-del-Rio, F., Ortega-Santiago, R., Jimenez-Garcia, R., Arendt-Nielsen, L., \& Svensson, P. (2010). Bilateral thermal hyperalgesia in trigeminal and extratrigeminal regions in patients with myofascial temporomandibular disorders. Experimental Brain Research, 202, 171-179. https://doi.org/10.1007/s00221-009-2121-x

Finnerup, N. B., Haroutounian, S., Kamerman, P., Baron, R., Bennett, D. L. H., Bouhassira, D., Cruccu, G., Freeman, R., Hansson, P., Nurmikko, T., Raja, S. N., Rice, A. S. C., Serra, J., Smith, B. H., Treede, R.-D., \& Jensen, T. S. (2016). Neuropathic pain: An updated grading system for research and clinical practice. Pain, 157. https://doi.org/10.1097/j.pain.0000000000 000492

Gaab, J., Baumann, S., Budnoik, A., Gmünder, H., Hottinger, N., \& Ehlert, U. (2005). Reduced reactivity and enhanced negative feedback sensitivity of the hypothalamus-pituitary-adrenal axis in chronic whiplash-associated disorder. Pain, 119, 219-224. https://doi.org/10.1016/j.pain.2005.10.001

Geber, C., Magerl, W., Fondel, R., Fechir, M., Rolke, R., Vogt, T., Treede, R. D., \& Birklein, F. (2008). Numbness in clinical and experimental pain-A cross-sectional study exploring the mechanisms of reduced tactile function. Pain, 139, 73-81. https:// doi.org/10.1016/j.pain.2008.03.006

Georgopoulos, V., Akin-Akinyosoye, K., Zhang, W., McWilliams, D. F., Hendrick, P., \& Walsh, D. A. (2019). Quantitative sensory testing and predicting outcomes for musculoskeletal pain, disability, and negative affect: A systematic review and meta-analysis. Pain, 160, 1920-1932. https://doi.org/10.1097/j. pain.0000000000001590

Goldsmith, R., Wright, C., Bell, S. F., \& Rushton, A. (2012). Cold hyperalgesia as a prognostic factor in whiplash associated disorders: A systematic review. Manual Therapy, 17, 402-410. https://doi.org/10.1016/j.math.2012.02.014

Harte, S. E., Harris, R. E., \& Clauw, D. J. (2018). The neurobiology of central sensitization. Journal of Applied Biobehavioral Research, 23, e12137. https://doi.org/10.1111/jabr.12137

Hartling, L., Brison, R. J., Ardern, C., \& Pickett, W. (2001). Prognostic value of the Quebec classification of Whiplash-associated disorders. Spine, 2001(26), 36-41. https://doi.org/10.1097/00007 632-200101010-00008

Heldestad, V., Linder, J., Sellersjö, L., \& Nordh, E. (2010). Reproducibility and influence of test modality order on thermal perception and thermal pain thresholds in quantitative sensory testing. Clinical Neurophysiology, 121, 1878-1885. https://doi. org/10.1016/j.clinph.2010.03.055

Herren-Gerber, R., Weiss, S., Arendt-Nielsen, L., Petersen-Felix, S., Di Stefano, G., Radanov, B. P., \& Curatolo, M. (2004). 
Modulation of central hypersensitivity by nociceptive input in chronic pain after whiplash injury. Pain Medicine, 5, 366-376. https://doi.org/10.1111/j.1526-4637.2004.04055.x.

Hübscher, M., Moloney, N., Rebbeck, T., Traeger, A., \& Refshauge, K. M. (2014). Contributions of mood, pain catastrophizing, and cold hyperalgesia in acute and chronic low back pain: A comparison with pain-free controls. Clinical Journal of Pain, 30, 886-893. https://doi.org/10.1097/AJP.0000000000000045

Järvinen, T. A., Järvinen, M., \& Kalimo, H. (2014). Regeneration of injured skeletal muscle after the injury. Muscle Ligaments and Tendons Journal, 3, 337-345. https://doi.org/10.32098/ mltj.04.2013.16

Ji, R.-R., Nackley, A., Huh, Y., Terrando, N., \& Maixner, W. (2018). Neuroinflammation and central sensitization in chronic and widespread pain. Anesthesiology, 129, 343-366. https://doi. org/10.1097/ALN.0000000000002130

Jorgensen, R., Ris, I., Falla, D., \& Juul-Kristensen, B. (2014). Reliability, construct and discriminative validity of clinical testing in subjects with and without chronic neck pain. BMC Musculoskeletal Disorders, 15. https://doi.org/10.1186/1471-2474-15-408

Kaale, B. R., Krakenes, J., Albrektsen, G., \& Wester, K. (2005). Whiplash-associated disorders impairment rating: Neck disability index score according to severity of MRI findings of ligaments and membranes in the upper cervical spine. Journal of Neurotrauma, 22, 466-475. https://doi.org/10.1089/ neu.2005.22.466

Kamper, S. J., Maher, C. G., Hush, J. M., Pedler, A., \& Sterling, M. (2011). Relationship between pressure pain thresholds and pain ratings in patients with whiplash-associated disorders. Clinical Journal of Pain, 27, 495-501. https://doi.org/10.1097/ AJP.0b013e31820e1185

Kamper, S. J., Rebbeck, T. J., Maher, C. G., McAuley, J. H., \& Sterling, M. (2008). Course and prognostic factors of whiplash: A systematic review and meta-analysis. Pain, 138, 617-629. https:// doi.org/10.1016/j.pain.2008.02.019

Kasch, H., Hjorth, T., Svensson, P., Nyhuus, L., \& Jensen, T. S. (2002). Temporomandibular disorders after whiplash injury: A controlled, prospective study. Journal of Orofacial Pain, 16, 118-128.

Kasch, H., Qerama, E., Bach, F. W., \& Jensen, T. S. (2005). Reduced cold pressor pain tolerance in non-recovered whiplash patients: A 1-year prospective study. European Journal of Pain, 9, 561569. https://doi.org/10.1016/j.ejpain.2004.11.011

Kasch, H., Qerama, E., Kongsted, A., Bach, F. W., Bendix, T., \& Jensen, T. S. (2008). Deep muscle pain, tender points and recovery in acute whiplash patients: A 1-year follow-up study. Pain, 140, 65-73. https://doi.org/10.1016/j.pain.2008.07.008

Kasch, H., Stengaard-Pedersen, K., Arendt-Nielsen, L., \& Jensen, T. S. (2001). Pain thresholds and tenderness in neck and head following acute whiplash injury: A prospective study. Cephalalgia, 21, 189-197. https://doi.org/10.1046/j.1468-2982.2001.00179.x

Kosek, E., Clauw, D., Nijs, J., Baron, R., Gilron, I., Harris, R. E., Mico, J. A., Rice, A. S., \& Sterling, M. (2021). Chronic nociplastic pain affecting the musculoskeletal system: Clinical criteria and grading system. Pain. https://doi.org/10.1097/j.pain.00000 00000002324

Kosek, E., Cohen, M., Baron, R., Gebhart, G. F., Mico, J.-A., Rice, A. S. C., Rief, W., \& Sluka, A. K. (2016). Do we need a third mechanistic descriptor for chronic pain states? Pain, 157(7), 13821386. https://doi.org/10.1097/j.pain.0000000000000507
Koulouris, A. E., Edwards, R. R., Dorado, K., Schreiber, K. L., Lazaridou, A., Rajan, S., White, J., Garcia, J., Gibbons, C., \& Freeman, R. (2020). Reliability and validity of the Boston bedside quantitative sensory testing battery for neuropathic pain. Pain Medicine, 21, 2336-2347. https://doi.org/10.1093/pm/ pnaa192

Lakens, D. (2013). Calculating and reporting effect sizes to facilitate cumulative science: A practical primer for t-tests and ANOVAs. Frontiers in Psychology, 4, 863. https://doi.org/10.3389/ fpsyg.2013.00863.

Latremoliere, A., \& Woolf, C. J. (2009). Central sensitization: A generator of pain hypersensitivity by central neural plasticity. The Journal of Pain, 10, 895-926. https://doi.org/10.1016/j. jpain.2009.06.012.

Lim, E. C., Sterling, M., Stone, A., \& Vicenzino, B. (2011). Central hyperexcitability as measured with nociceptive flexor reflex threshold in chronic musculoskeletal pain: A systematic review. Pain, 152, 1811-1820. https://doi.org/10.1016/j. pain.2011.03.033.

Lluch, E., Torres, R., Nijs, J., \& Van Oosterwijck, J. (2014). Evidence for central sensitization in patients with osteoarthritis pain: A systematic literature review. European Journal of (United Kingdom), 18, 1367-1375. https://doi. org/10.1002/j.1532-2149.2014.499.x.

Lord, S. M., Barnsley, L., Wallis, B. J., \& Bogduk, N. (1996). Chronic cervical zygapophysial joint pain after whiplash. A placebocontrolled prevalence study. Spine, 21, 1737-1744. discussion 1744-1735. https://doi.org/10.1097/00007632-19960 8010-00005.

Magerl, W., \& Treede, R. D. (2004). Secondary tactile hypoesthesia: A novel type of pain-induced somatosensory plasticity in human subjects. Neuroscience Letters, 361, 136-139. https://doi. org/10.1016/j.neulet.2003.12.001.

Marcuzzi, A., Dean, C. M., Wrigley, P. J., \& Hush, J. M. (2015). Early changes in somatosensory function in spinal pain: A systematic review and meta-analysis. Pain, 156, 203-214. https://doi. org/10.1097/01.j.pain.0000460300.10583.f6.

McLean, S. A. (1976). The potential contribution of stress systems to the transition to chronic whiplash-associated disorders. Spine, 36, S226-232. https://doi.org/10.1097/BRS.0b013e3182 $387 \mathrm{fb} 4$

Meeus, M., Vervisch, S., De Clerck, L. S., Moorkens, G., Hans, G., \& Nijs, J. (2012). Central sensitization in patients with rheumatoid arthritis: A systematic literature review. Seminars in Arthritis and Rheumatism, 41, 556-567. https://doi.org/10.1016/j.semar thrit.2011.08.001.

Merskey, H. (1994). Part III pain terms, a current list with definitions and notes on usage. Classification of Chronic pain-descriptions of Chronic Pain Syndromes and Definitions of Pain Terms, pp. 207-214.

Moher, D., Liberati, A., Tetzlaff, J., \& Altman, D. G. (2010). Preferred reporting items for systematic reviews and meta-analyses: The PRISMA statement. International Journal of Surgery, 8, 336341. https://doi.org/10.1016/j.ijsu.2010.02.007.

Moriwaki, K., \& Yuge, O. (1999). Topographical features of cutaneous tactile hypoesthetic and hyperesthetic abnormalities in chronic pain. Pain, 81, 1-6. https://doi.org/10.1016/S0304 -3959(98)00257-7.

Moss, P., Knight, E., \& Wright, A. (2016). Subjects with knee osteoarthritis exhibit widespread hyperalgesia to pressure and 
cold. PLoS One, 11, e0147526. https://doi.org/10.1371/journ al.pone. 0147526

Nebel, K., Stude, P., Ludecke, C., Wiese, H., Diener, H. C., \& Keidel, M. (2005). Prospective PC-interactive pressure algesimetry of post-traumatic neck pain after whiplash injury. Cephalalgia, 25, 205-213. https://doi.org/10.1111/j.1468-2982.2004.00842.x.

Neddermeyer, T. J., Flühr, K., \& Lötsch, J. (2008). Principle components analysis of pain thresholds to thermal, electrical, and mechanical stimuli suggests a predominant common source of variance. Pain, 138, 286-291. https://doi.org/10.1016/j. pain.2007.12.015.

Nijs, J., Goubert, D., \& Ickmans, K. (2016). Recognition and treatment of central sensitization in chronic pain patients: Not limited to specialized care. Journal of Orthopaedic \& Sports Physical Therapy, 46, 1024-1028. https://doi.org/10.2519/ jospt.2016.0612.

Olango, W. M., \& Finn, D. P. (2014). Neurobiology of stress-induced hyperalgesia. Current Topics in Behavioral Neurosciences, 20, 251-280.

Olivegren, H., Jerkvall, N., Hagstrom, Y., \& Carlsson, J. (1999). The long-term prognosis of whiplash-associated disorders (WAD). European Spine Journal, 8, 366-370. https://doi.org/10.1007/ s005860050189.

Price, D. D., Hu, J. W., Dubner, R., \& Gracely, R. H. (1977). Peripheral suppression of first pain and central summation of second pain evoked by noxious heat pulses. Pain, 3, 57-68. https://doi. org/10.1016/0304-3959(77)90035-5.

Prushansky, T., Handelzalts, S., \& Pevzner, E. (2007). Reproducibility of pressure pain threshold and visual analog scale findings in chronic whiplash patients. Clinical Journal of Pain, 23, 339345. https://doi.org/10.1097/AJP.0b013e31803157ff.

Reimer, M., Forstenpointner, J., Hartmann, A., Otto, J. C., Vollert, J., Gierthmühlen, J., Klein, T., Hüllemann, P., \& Baron, R. Sensory bedside testing: a simple stratification approach for sensory phenotyping. Pain Reports, 5(3), e820. https://doi.org/10.1097/ PR9.0000000000000820.

Rolke, R., Magerl, W., Campbell, K. A., Schalber, C., Caspari, S., Birklein, F., \& Treede, R. D. (2006). Quantitative sensory testing: A comprehensive protocol for clinical trials. European Journal of Pain, 10, 77-88. https://doi.org/10.1016/j.ejpain.2005.02.003.

Ronnen, H. R., de Korte, P. J., Brink, P. R., van der Bijl, H. J., Tonino, A. J., \& Franke, C. L. (1996). Acute whiplash injury: Is there a role for MR imaging? A prospective study of 100 patients. Radiology, 201, 93-96. https://doi.org/10.1148/radiology.201.1.8816527.

Sarrami, P., Armstrong, E., Naylor, J. M., \& Harris, I. A. (2017). Factors predicting outcome in whiplash injury: A systematic meta-review of prognostic factors. Journal of Orthopaedics and Traumatology, 18, 9-16. https://doi.org/10.1007/s1019 5-016-0431-x

Schneider, G. M., Smith, A. D., Hooper, A., Stratford, P., Schneider, K. J., Westaway, M. D., Frizzell, B., \& Olson, L. (2010). Minimizing the source of nociception and its concurrent effect on sensory hypersensitivity: An exploratory study in chronic whiplash patients. BMC Musculoskeletal Disorders, 11, 29. https://doi. org/10.1186/1471-2474-11-29

Scholten-Peeters, G. G. M., Verhagen, A. P., Bekkering, G. E., Van Der Windt, D. A. W. M., Barnsley, L., Oostendorp, R. A. B., \& Hendriks, E. J. M. (2003). Prognostic factors of whiplashassociated disorders: A systematic review of prospective cohort studies. Pain, 104, 303-322. https://doi.org/10.1016/S0304 -3959(03)00050-2

Serrano-Munoz, D., Galan-Arriero, I., Avila-Martin, G., GomezSoriano, J., Florensa, J., Garcia-Peris, A., Romero-Munoz, L. M., Barriga-Martin, A., \& Taylor, J. (2019). Deficient inhibitory endogenous pain modulation correlates with periaqueductal gray matter metabolites during chronic whiplash injury. Clinical Journal of Pain, 35, 668-677. https://doi.org/10.1097/ AJP.0000000000000722

Stammler, T., De Col, R., Seifert, F., \& Maihöfner, C. (2008). Functional imaging of sensory decline and gain induced by differential noxious stimulation. NeuroImage, 42, 1151-1163. https://doi.org/10.1016/j.neuroimage.2008.05.048

Sterling, M. (2010). Differential development of sensory hypersensitivity and a measure of spinal cord hyperexcitability following whiplash injury. Pain, 150, 501-506. https://doi.org/10.1016/j. pain.2010.06.003

Sterling, M., Hendrikz, J., \& Kenardy, J. (2010). Compensation claim lodgement and health outcome developmental trajectories following whiplash injury: a prospective study. Pain, 150, 22-28. https://doi.org/10.1016/j.pain.2010.02.013

Sterling, M., Jull, G., \& Kenardy, J. (2006). Physical and psychological factors maintain long-term predictive capacity post-whiplash injury. Pain, 122, 102-108. https://doi.org/10.1016/j.pain.2006.01.014

Sterling, M., Jull, G., Vicenzino, B., \& Kenardy, J. (2004). Characterization of acute whiplash-associated disorders. Spine, 2004(29), 182-188. https://doi.org/10.1097/01.BRS.00001 05535.12598.AE

Sterling, M., Jull, G., Vicenzino, B., \& Kenardy, J. (2003). Sensory hypersensitivity occurs soon after whiplash injury and is associated with poor recovery. Pain, 104, 509-517. https://doi. org/10.1016/S0304-3959(03)00078-2

Sterling, M., Jull, G., Vicenzino, B., Kenardy, J., \& Darnell, R. (2005). Physical and psychological factors predict outcome following whiplash injury. Pain, 114, 141-148. https://doi.org/10.1016/j. pain.2004.12.005

Sterling, M., \& Pedler, A. (2009). A neuropathic pain component is common in acute whiplash and associated with a more complex clinical presentation. Manual Therapy, 14, 173-179. https://doi. org/10.1016/j.math.2008.01.009

Sterling, M., Smeets, R., Keijzers, G., Warren, J., \& Kenardy, J. (2019). Physiotherapist-delivered stress inoculation training integrated with exercise versus physiotherapy exercise alone for acute whiplash-associated disorder (StressModex): A randomised controlled trial of a combined psychological/physical intervention. British Journal of Sports Medicine, 53, 1240-1247. https:// doi.org/10.1136/bjsports-2018-100139

Sterling, M., Treleaven, J., \& Jull, G. (2002). Responses to a clinical test of mechanical provocation of nerve tissue in whiplash associated disorder. Manual Therapy, 7, 89-94. https://doi. org/10.1054/math.2002.0443

Stone, A. M., Vicenzino, B., Lim, E. C., \& Sterling, M. (2013). Measures of central hyperexcitability in chronic whiplash associated disorder-A systematic review and meta-analysis. Manual Therapy, 18, 111-117. https://doi.org/10.1016/j. math.2012.07.009

Uddin, Z., \& MacDermid, J. C. (2016). Quantitative sensory testing in chronic musculoskeletal pain. Pain Medicine, 17, 1694-1703. https://doi.org/10.1093/pm/pnv105 
Van Oosterwijck, J., Nijs, J., Meeus, M., \& Paul, L. (2013). Evidence for central sensitization in chronic whiplash: A systematic literature review. European Journal of Pain, 17, 299-312. https:// doi.org/10.1002/j.1532-2149.2012.00193.x

Vollert, J., Mainka, T., Baron, R., Enax-Krumova, E. K., Hüllemann, P., Maier, C., Pfau, D. B., Tölle, T., \& Treede, R. D. (2015). Quality assurance for Quantitative Sensory Testing laboratories: Development and validation of an automated evaluation tool for the analysis of declared healthy samples. Pain, 156, 2423-2430. https://doi.org/10.1097/j. pain. 0000000000000300

Walter, S. D., \& Yao, X. (2007). Effect sizes can be calculated for studies reporting ranges for outcome variables in systematic reviews. Journal of Clinical Epidemiology, 60, 849-852. https:// doi.org/10.1016/j.jclinepi.2006.11.003

Walton, D. M., \& Elliott, J. M. (2017). An integrated model of chronic whiplash-associated disorder. Journal of Orthopaedic and Sports Physical Therapy, 47, 462-471. https://doi.org/10.2519/ jospt.2017.7455

Walton, D. M., Macdermid, J. C., Giorgianni, A. A., Mascarenhas, J. C., West, S. C., \& Zammit, C. A. (2013). Risk factors for persistent problems following acute whiplash injury: Update of a systematic review and meta-analysis. Journal of Orthopaedic and Sports Physical Therapy, 43, 31-43. https://doi.org/10.2519/ jospt.2013.4507

Wasner, G. L., \& Brock, J. A. (2008). Determinants of thermal pain thresholds in normal subjects. Clinical Neurophysiology, 119, 2389-2395. https://doi.org/10.1016/j.clinph.2008.07.223
Woolf, C. J. (2011). Central sensitization: Implications for the diagnosis and treatment of pain. Pain, 152, S2-15. https://doi. org/10.1016/j.pain.2010.09.030

Yarnitsky, D., Arendt-Nielsen, L., Bouhassira, D., Edwards, R. R., Fillingim, R. B., Granot, M., Hansson, P., Lautenbacher, S., Marchand, S., \& Wilder-Smith, O. (2010). Recommendations on terminology and practice of psychophysical DNIC testing. European Journal of Pain, 14, 339. https://doi.org/10.1016/j.ejpain.2010.02.004

Zorina-Lichtenwalter, K., Meloto, C. B., Khoury, S., \& Diatchenko, L. (2016). Genetic predictors of human chronic pain conditions. Neuroscience, 338, 36-62. https://doi.org/10.1016/j.neuroscien ce.2016.04.041

\section{SUPPORTING INFORMATION}

Additional supporting information may be found online in the Supporting Information section.

How to cite this article: Bontinck, J., Lenoir, D., Cagnie, B., Murillo, C., Timmers, I., Cnockaert, E., Bernaers, L., Meeus, M., \& Coppieters, I. (2022). Temporal changes in pain processing after whiplash injury, based on Quantitative Sensory Testing: A systematic review. European Journal of Pain, 26, 227-245. https://doi.org/10.1002/ejp.1858 